\title{
Application of prolonged microdialysis sampling in carboplatin-treated cancer patients
}

\author{
Inge R. H. M. Konings · Frederike K. Engels • \\ Stefan Sleijfer · Jaap Verweij · Erik A. C. Wiemer • \\ Walter J. Loos
}

Received: 18 September 2008/Accepted: 1 December 2008/Published online: 20 December 2008

(C) The Author(s) 2008. This article is published with open access at Springerlink.com

\begin{abstract}
Purpose To better understand the mechanisms underlying (in)sensitivity of tumors to anticancer drugs, assessing intra-tumor drug pharmacokinetics (PKs) could be important. We explored the feasibility of microdialysis in tumor tissue for multiple days in a clinical setting, using carboplatin as model drug.

Methods Plasma and microdialysate samples from tumor and adipose normal tissues were collected up to $47 \mathrm{~h}$ after dosing in eight carboplatin-treated patients with an accessible (sub)cutaneous tumor.

Results Pharmacokinetics were evaluable in tumor tissue in $6 / 8$ patients and in adipose normal tissue in $3 / 8$ patients. Concentration-time curves of unbound platinum in both the tissues followed the pattern of the curves in plasma, with exposure ratios of tissue versus plasma ranging from 0.64 to 1.46 .

Conclusions Microdialysis can be successfully employed in ambulant patients for multiple days, which enables one to study tissue PK of anticancer drugs in normal and malignant tissues in more detail.
\end{abstract}

Keywords Microdialysis - Clinical oncology · Pharmacokinetics $\cdot$ Target site $\cdot$ Carboplatin

The article was presented in part at the 2008 Annual Meeting of the American Society for Clinical Pharmacology and Therapeutics, 2-5 April 2008, Orlando, FL; Clinical Pharmacology \& Therapeutics 83, S51 (abstract PII-31), 2008.

I. R. H. M. Konings ( $₫) \cdot$ F. K. Engels · S. Sleijfer ·

J. Verweij - E. A. C. Wiemer · W. J. Loos

Department of Medical Oncology, Erasmus University Medical

Center, Room HE-126, 's Gravendijkwal 230,

3015 CE Rotterdam, The Netherlands

e-mail: i.konings@erasmusmc.nl

\section{Introduction}

In clinical oncology, many treatment regimens are in part based on acquired concentrations of the involved anticancer drugs measured in blood. This so-called pharmacokinetic (PK) profile in the peripheral circulation has been established for many of the currently used cytotoxic drugs, but varies largely between patients because of inter-individual differences in capacity to metabolize and eliminate the administered agent. Furthermore, the obtained blood PK profile may not be informative enough or may not, per definition, be related to tumor or tissue concentrations. This was demonstrated, e.g., in mice-bearing tumor xenografts treated with docetaxel, camptothecin analogues and topotecan, respectively, where plasma, tissue and tumor concentrations differed considerably [1-3]. Also, clinical parameters such as drug efficacy and toxicity are quite often not concordantly associated. Consequently, it would be interesting to gain more information about the pharmacokinetic processes at the tumor site itself.

The technique of microdialysis allows for the evaluation of tumor and tissue disposition of drugs. Microdialysis is a minimally invasive sampling method based on the diffusion of analytes from the interstitial compartment [i.e. extracellular fluid (ECF)] through a semipermeable membrane. After inserting a microdialysis catheter into the selected tissue followed by perfusion with an isotonic fluid, the perfusate, the exchange of endogenous and/or exogenous compounds from the ECF into the perfusate takes place following their concentration gradient. The solution that exits the catheter, the microdialysate, is then collected for analysis (Fig. 1a). Since there is no net fluid exchange over the membrane during microdialysis, continuous sampling for prolonged periods is possible without interfering with the pharmacokinetic behavior of the drug [4]. 
The concept of microdialysis has been optimized in neurological research where microdialysis was used to monitor neurotransmitter concentrations in brain tissue. Microdialysis was shown to be applicable in oncology as well. Clinical drug disposition studies using microdialysis were performed with several anticancer drugs, such as 5-fluorouracil [5], capecitabine [6], cisplatin [7], carboplatin [8], dacarbazine [9] and methotrexate [10, 11].

However, in these studies with anticancer drugs performed till now, the pharmacokinetic data derived using microdialysis were collected only during a relative short period of time, i.e. up to a maximum of $4 \mathrm{~h}$, which might be too short to obtain informative pharmacokinetic profiles. Therefore, in the present study, the feasibility of microdialysis was studied for multiple days. Carboplatin was chosen as model drug since this drug exists in two distinguishable fractions in the plasma compartment: the free fraction dissolved in plasma water (i.e. unbound fraction), which is thought to penetrate tissues, and the irreversibly to plasma protein bound fraction. Given the relative slow plasma clearance of the unbound fraction of carboplatin [12] in comparison with for example the unbound fraction of the other widely used platinum containing anticancer agent cisplatin, it was expected that carboplatin-derived platinum concentrations could be quantitated in the dialysates for several days after the administration. Investigation of normal tissue was conducted as well to compare the data obtained through microdialysis with PK data from the tumor site.

\section{Patients and methods}

Patient selection criteria

Patients who had a (sub)cutaneous primary tumor or metastasis and for whom carboplatin-based therapy was a viable treatment option were eligible for the study. The (sub)cutaneous lesion had to be of sufficient size (i.e. $\geq 20 \mathrm{~mm}$ ) and readily accessible for catheter implantation. Other inclusion criteria included: no use of therapeutic doses of anticoagulants (prophylactic use was allowed); no previous serious allergic reactions to platinum compounds; WHO performance status $\leq 1$; age $\geq 18$ years; absolute neutrophil count $\geq 1.5 \times 10^{9} \mathrm{~L}^{-1}$; absolute platelet count $\geq 100 \times 10^{9} \mathrm{~L}^{-1} ;$ creatinine clearance $\geq 60 \mathrm{~mL} / \mathrm{min}$; no other serious illness or medical unstable condition requiring treatment or history of psychiatric disorder that would prohibit the understanding and giving of informed consent. This singlecenter study was approved by the ethical committee of the Erasmus Medical Center (Rotterdam, the Netherlands) and was performed in accordance with the standards laid down in the 1964 Declaration of Helsinki and its later amendments. All patients gave written informed consent.

\section{Administration of carboplatin}

Carboplatin (Carbosin, Pharmachemie, Haarlem, the Netherlands) was administered as a $1 \mathrm{~h}$ intravenous infusion at an AUC of $6(\mathrm{mg} \mathrm{min}) / \mathrm{mL}$ based on the Calvert formula [13]. To prevent allergic reactions and nausea and vomiting, a premedication schedule consisting of dexamethasone, clemastine, ranitidine and granisetron was administered intravenously prior to the start of the carboplatin infusion. In case carboplatin was combined with another cytotoxic agent (e.g. paclitaxel), this second agent was administered approximately $48 \mathrm{~h}$ after the administration of carboplatin.

Plasma pharmacokinetic and microdialysis sampling were performed during a single treatment course.
A

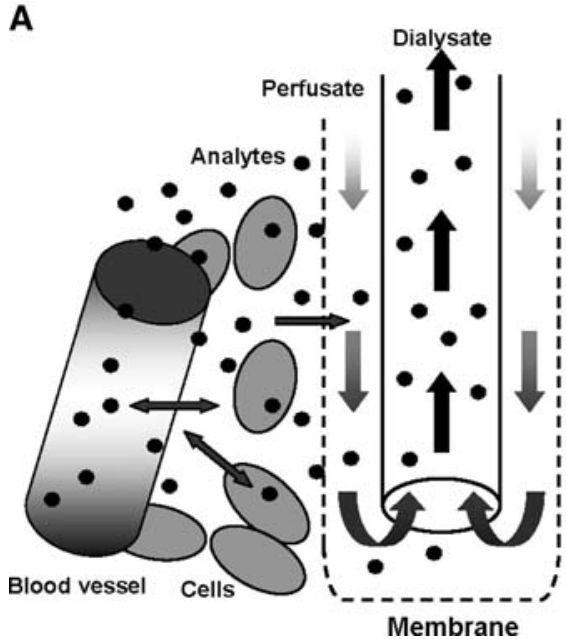

B

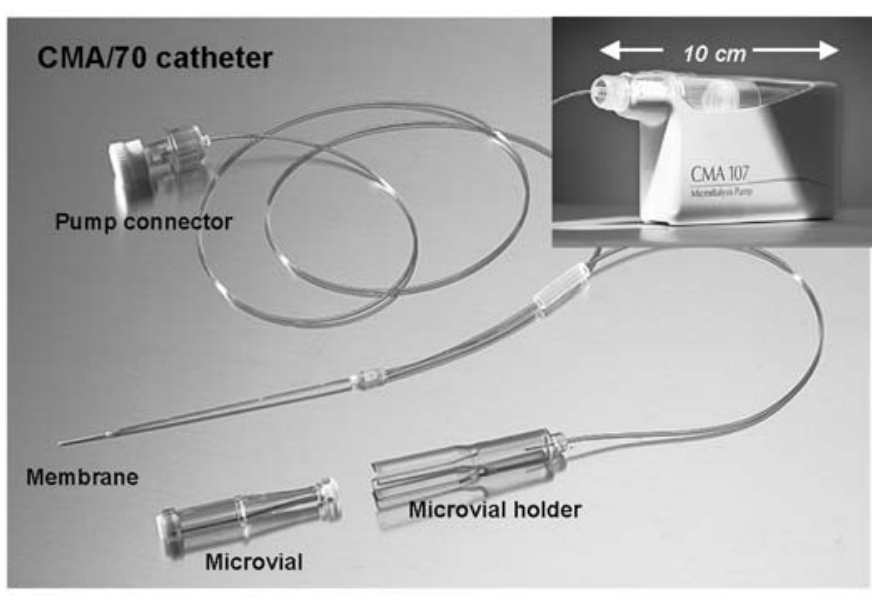

Fig. 1 Schematic representation of a microdialysis probe and the diffusion path of an analyte in tissue (a) and microdialysis instruments (b) 
Microdialysis instruments and catheter insertion

The microdialysis catheters (CMA 70, brain catheters), pumps (CMA 107, flow rate adjustable) and microdialysis consumables were purchased from CMA/Microdialysis AB (Solna, Sweden; Fig. 1b). The applied microdialysis instruments were, at least at start of the clinical study, the only CE-labeled devices according to the Medical Device Directive (MDD) for the use in peripheral tissue and have been approved for clinical use. Prior to catheter insertion, the surface of the skin was locally anaesthetized with topical lidocaine/prilocaine cream and thereafter disinfected according to local procedures. Microdialysis catheter insertion took place according to the procedure previously described by Müller et al. [14]. Each patient had one microdialysis catheter inserted in a suitable (sub)cutaneous tumor lesion and a second one into healthy abdominal subcutaneous adipose tissue. Correct positioning of the catheter at the tumor site was determined by ultrasound.

After implantation, the microdialysis syringe was filled with $2.5 \mathrm{~mL}$ of Ringer's solution $\left(147 \mathrm{mmol} / \mathrm{L} \mathrm{Na}^{+}\right.$, $2.25 \mathrm{mmol} / \mathrm{L} \mathrm{Ca}^{2+}, 4.00 \mathrm{mmol} / \mathrm{L} \mathrm{K}^{+}$, and $156 \mathrm{mmol} / \mathrm{L} \mathrm{Cl}$; Baxter, Utrecht, the Netherlands), connected to the microdialysis catheter and then placed in the pump. The pump automatically started with a 5-6-min flush period (flow $15 \mu \mathrm{L} / \mathrm{min}$ ) after which the flow automatically decreased to the preset flow rate of $0.5 \mu \mathrm{L} / \mathrm{min}$.

Since implantation of the microdialysis catheter could cause adverse tissue reactions (i.e. inflammatory effects), the catheter was implanted the day before the carboplatin infusion to allow enough time to let these tissue reactions subside [15]. Earlier studies showed that the minimally invasive technique of microdialysis implantation has generally no effect on the performance of the implanted microdialysis catheters [14-16]. Sampling with microdialysis probes was started on the day of implantation (day 0 ) and up to a maximum of $48 \mathrm{~h}$ after carboplatin infusion. Carboplatin infusion was started $2 \mathrm{~h}$ after the recovery determination on day 1 , during which time period carboplatin was washed out from the periprobe fluid (data not shown). Figure 2 depicts the order of procedures undertaken in this study.

\section{Assessment of probe recovery}

As microdialysis is not performed under equilibrium conditions, the concentration of the drug in the dialysate will be different from that in the fluid around the probe (i.e. in the tissue of investigation). The relationship between the dialysate concentration and the concentration around the probe is called relative recovery [17], which can be depicted in a ratio. As the rates of diffusion of most analytes differ between aqueous solutions and tissue, adequate validation of the in vivo recovery is required. Solely in vitro calibration of a microdialysis probe is insufficient, but is useful to investigate (a) the potential absorption of analyte to the microdialysis probe [18] and (b) the potential effect of the analyte concentration, at clinically relevant concentrations, on the recovery.

The in vitro recovery of the CMA 70 catheters was assessed at ambient temperature using the extraction recovery (Eq. 1) as well as the retrodialysis (Eq. 2) method:

$$
\begin{aligned}
\text { Recovery }= & \text { Conc }_{\text {dialysate }} / \text { Conc }_{\text {solution }} \times 100 \% \\
\text { Recovery }= & \left(\text { Conc }_{\text {perfusate }}-\text { Conc }_{\text {dialysate }}\right) / \text { Conc }_{\text {perfusate }} \\
& \times 100 \%
\end{aligned}
$$

Using the extraction recovery method, the recovery was determined at concentrations of 2.0 and $20 \mu \mathrm{g} / \mathrm{mL}$ carboplatin (Carbosin, Pharmachemie, Haarlem, the Netherlands) in Ringer's solution at a flow rate of $0.5 \mu \mathrm{L} / \mathrm{min}$, at a concentration of $20 \mu \mathrm{g} / \mathrm{mL}$ carboplatin at flow rates of $0.5,1.0$ and $2.0 \mu \mathrm{L} / \mathrm{min}$ and at a concentration of $20 \mu \mathrm{g} / \mathrm{mL}$ carboplatin at a flow rate of $0.5 \mu \mathrm{L} / \mathrm{min}$ during 3 days. Using the retrodialysis method, the recovery was assessed at a concentration of $20 \mu \mathrm{g} / \mathrm{mL}$ carboplatin at a flow rate of $0.5 \mu \mathrm{L} / \mathrm{min}$. Three consecutive 30 min samples were taken for each experiment after an equilibration time of at least $30 \mathrm{~min}$. Samples were stored at $T<-20^{\circ} \mathrm{C}$ until analysis.

The in vivo recovery for each inserted probe was assessed on the morning of day 1 , before the start of the infusion, using the retrodialysis method by perfusing a Ringer's solution containing $20 \mu \mathrm{g} / \mathrm{mL}$ of carboplatin through each inserted probe at a flow rate of $0.5 \mu \mathrm{L} / \mathrm{min}$ (patient 1 perfused at 0.5 and $1.0 \mu \mathrm{L} / \mathrm{min}$ ). After equilibration for 15-30 min, 3-5 dialysate samples were collected every $30 \mathrm{~min}$ and processed as described above. The recovery (Eq. 2) was calculated as the mean of the three to five observations.

\section{Microdialysis sampling}

As there is a constant flow of Ringer's solution through the membrane of the catheter, dialysate is sampled continuously. Samples are collected in microvials (Fig. 1b) during sample periods varying from $1 \mathrm{~h}$ during and shortly after the carboplatin infusion up to $3 \mathrm{~h}$ at later time points. Samples were stored directly at the bed-side of the patient at $T<-20^{\circ} \mathrm{C}$. The dialysates were collected by centrifugation of the microvials upside down in micro-centrifuge reaction vials for $1 \mathrm{~min}$ at $500 \times \mathrm{g}$, after which they were stored at $T<-70^{\circ} \mathrm{C}$ until analysis. 


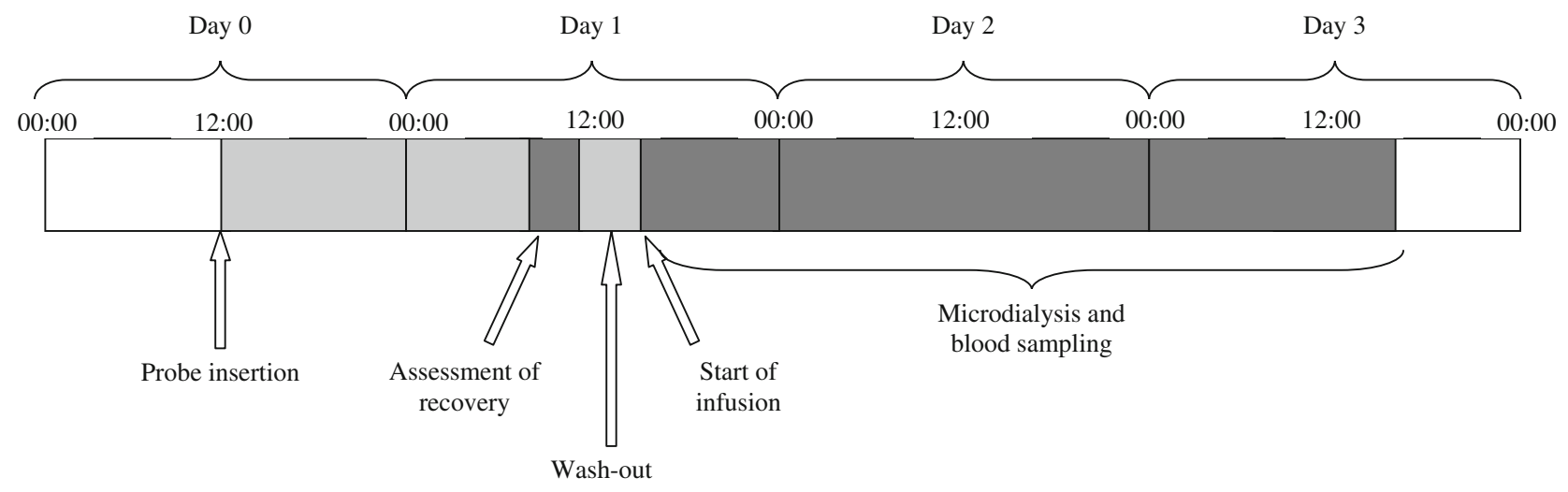

Fig. 2 Time frame describing order of procedures

\section{Blood sampling}

For carboplatin plasma pharmacokinetic analysis, blood samples were collected in the presence of lithium heparin as anticoagulant at the following time points: before the start of the intravenous carboplatin infusion, $30 \mathrm{~min}$ after to start of infusion, at the end of the $1 \mathrm{~h}$ infusion and at 1 , $2,4,6,8,11,23,35$ and $47 \mathrm{~h}$ after the end of infusion. Within 15 min after collection, plasma was separated by centrifugation at $3,000 \times g$ for $10 \mathrm{~min}$. Subsequently, 500$\mu \mathrm{L}$ aliquots of the plasma supernatant were mixed with 1.0$\mathrm{mL}$ aliquots of ice-cold $\left(-20^{\circ} \mathrm{C}\right)$ ethanol and stored at $T<-20^{\circ} \mathrm{C}$. Ethanolic supernatant was collected by centrifugation at $18,000 \times g$ for $5 \mathrm{~min}$ after which the clear supernatant was stored at $T<-70^{\circ} \mathrm{C}$ until analysis. The remaining plasma supernatant, for the analysis of carboplatin-derived total platinum, was stored at $T<-70^{\circ} \mathrm{C}$ until analysis.

\section{Carboplatin analysis}

For the analysis of carboplatin-derived platinum in dialysate, the methodology was validated in the range of $0.0500-1.00 \mu \mathrm{g} / \mathrm{mL}$ (Method 1) and $0.200-5.00 \mu \mathrm{g} / \mathrm{mL}$ (Method 2) platinum in Ringer's solution. For Method 1, an aliquot of $100 \mu \mathrm{L}$ dialysate was mixed with an aliquot of $20 \mu \mathrm{L} 1.0 \% \mathrm{HNO}_{3}(\mathrm{v} / \mathrm{v})$, while for Method 2, an aliquot of $20 \mu \mathrm{L}$ dialysate was mixed with an aliquot of $100 \mu \mathrm{L}$ $0.2 \% \mathrm{HNO}_{3}(\mathrm{v} / \mathrm{v})$. A volume of $20 \mu \mathrm{L}$, in duplicate, was subsequently injected onto the graphite furnace of a Perkin Elmer Model 4110 ZL atomic absorption spectrophotometer (Uberlingen, Germany). Platinum peak areas were measured at $265.9 \mathrm{~nm}$. The lower limit of quantitation was established at $0.0500 \mu \mathrm{g} / \mathrm{mL}$ carboplatin-derived platinum for Method 1 and at $0.200 \mu \mathrm{g} / \mathrm{mL}$ for Method 2 .

Plasma concentrations of unbound carboplatin-derived platinum were determined according to a method as described for cisplatin-derived platinum [19]. This method was found to be equivalent to the ultrafiltration procedure as described earlier by Ma and Johnsson [20,21] and has been validated in our laboratory by direct comparison of ultrafiltration and ethanolic deproteinization On the day of analysis, aliquots of $1,000 \mu \mathrm{L}$ of the ethanolic supernatant were evaporated to dryness under nitrogen at $T=80^{\circ} \mathrm{C}$, and the residue was reconstituted in $200 \mu \mathrm{L}$ diluent (i.e. water containing $0.2 \%$ (v/v) Triton X-100 and $0.06 \%$ (w/v) cesium chloride), from which subsequent aliquots of $20 \mu \mathrm{L}$ were injected onto the graphite furnace as described above. The lower limit of quantitation was established at $0.0300 \mu \mathrm{g} / \mathrm{mL}$.

For total platinum analysis, plasma aliquots were accurately sixfold diluted in diluent (i.e. $100 \mu \mathrm{L}$ plasma mixed with $500 \mu \mathrm{L}$ diluent) from which subsequent aliquots of $20 \mu \mathrm{L}$ were also injected onto the graphite furnace. The lower limit of quantitation for total carboplatin-derived platinum in plasma was established at $0.200 \mu \mathrm{g} / \mathrm{mL}$.

\section{Pharmacokinetic data analysis}

Individual pharmacokinetic parameters for both total and unbound carboplatin-derived platinum in plasma as well as for carboplatin-derived platinum in dialysate were estimated using noncompartmental analysis using the software program WinNonLin 5.0 (Pharsight, CA, USA).

\section{Results}

Patients and microdialysis technique

Nine patients were included in the study between March and October 2007 and six patients were assessable for pharmacokinetic analysis of carboplatin in the ECF of tumor tissue. One patient never started therapy because of 
rapidly progressing disease. In another patient, there was leakage of the microdialysis catheter which led to inadequate sampling and therefore, catheters at both tumor and healthy tissue were removed. A third patient was considered non-evaluable because of a highly variable and decreasing recovery. The mean of the five recovery samples in that patient was $43.4 \%$ with a SD of $9.8 \%$, with an manifest decrease in time. A summary of demographic characteristics of the six patients assessable for pharmacokinetic analysis in the ECF of tumor tissue is presented in Table 1.

\section{Probe recovery}

Microdialysis is not performed under equilibrium conditions, so the concentration of the drug in the dialysate will be different from that in the ECF of tumor tissue. The relative recovery refers to the relation between the drug concentration in the dialysate and the estimated ECF drug concentration and is used to calculate the actual concentration in the ECF [17].

From initial in vitro recovery experiments (data not shown), it was anticipated that the microdialysis study could be performed at a flow rate of $1.0 \mu \mathrm{L} / \mathrm{min}$. At this flow rate, the recovery of carboplatin-derived platinum in tumor tissue of the first studied patient was low with a value of $26.5 \pm 3.0 \%$. In this patient the flow rate was subsequently decreased to $0.5 \mu \mathrm{L} / \mathrm{min}$ resulting in a higher recovery of $44.8 \pm 2.5 \%$. All subsequent patients were dialyzed at a flow rate of $0.5 \mu \mathrm{L} / \mathrm{min}$ and after equilibration for 15-30 min, 3-5 dialysate samples were collected every $30 \mathrm{~min}$

As shown in Table 2, the in vitro recoveries in the subsequently performed experiments were found to be higher compared to that observed in vivo recoveries, with values in the range of $94-98 \%$ observed at a flow rate of $0.5 \mu \mathrm{L} / \mathrm{min}$. By increasing the flow rates to 1.0 and $2.0 \mu \mathrm{L} / \mathrm{min}$, values of $81.4 \pm 3.1$ and $61.9 \pm 1.2 \%$ were observed, respectively. The in vitro recovery was

Table 1 Patient demographics of the six patients

\begin{tabular}{lllll}
\hline Patient & Age & Gender & Tumor type & ${\text { Tumor probe } \text { site }^{\mathrm{a}}}$ \\
\hline 1 & 49 & F & Melanoma & Thoracic wall \\
2 & 31 & M & Melanoma & Leg \\
3 & 53 & M & ACUP & Cervical lymph node \\
4 & 63 & M & Eccrine carcinoma & Axilla \\
5 & 65 & M & Esophagus & Supraclavicular lymph \\
& & & carcinoma & node \\
6 & 57 & F & ACUP & Thoracic wal \\
\hline
\end{tabular}

ACUP adenocarcinoma of unknown primary

${ }^{\text {a }}$ Probes in subcutaneous normal adipose tissue were all placed in the abdomen independent of the concentration tested and the method used, was found to be constant over three studied days and suggested carboplatin did not significantly bind to the microdialysis catheter.

At a flow rate of $0.5 \mu \mathrm{L} / \mathrm{min}$, the in vivo recovery in the six tumor tissue evaluable patients varied between 44.8 and $75.8 \%$ (Table 3) and was found to be very constant in each individual patient. The recovery in adipose subcutaneous tissue in the three normal tissue evaluable patients ranged between 25.5 and $62.9 \%$ (Table 3 ). In the remaining cases, one catheter was removed because of leakage, while in another patient due to incorrect flow setting of the pump, variable dialysate volumes and, as a result, highly variable recoveries were observed. In patient 6 , recovery decreased in subsequent dialysates, with a extremely low recovery of $0.4 \%$ in the fifth sample taken.

\section{Pharmacokinetics}

In Table 3, a summary of the pharmacokinetic data of carboplatin-derived total and unbound platinum in plasma as well as unbound platinum in the ECF of tumor and adipose normal tissue is presented. As shown in Fig. 3, the pharmacokinetic profiles of unbound platinum in the ECF of tumor and adipose tissue are identical to the profiles of unbound platinum in the plasma compartment. Carboplatin thus well distributed to the tumor and adipose tissue, while no sequestration of the drug in the ECF of the tissues was observed.

\section{Discussion}

Previously, several studies have explored microdialysis in cancer patients in order to study tissue PK of anti-tumor drugs. However in these studies, sampling was only conducted over a limited period of time (maximum of $4 \mathrm{~h}$ ). In this study, we have shown that microdialysis in cancer patients is also feasible for prolonged periods of time without restriction of patients' mobility. This allows examining anti-tumor drugs in more detail, in particular,

Table 2 In vitro recovery of carboplatin at a flow rate of $0.5 \mu \mathrm{L} / \mathrm{min}$ (data are presented as mean $\pm \mathrm{SD}$ of three measurements)

\begin{tabular}{llll}
\hline & $20 \mu \mathrm{g} / \mathrm{mL}$ carboplatin & $2.0 \mu \mathrm{g} / \mathrm{mL}$ carboplatin \\
\cline { 2 - 3 } & Extr. Rec. (\%) & Retrodialysis (\%) & Extr. Rec. (\%) \\
\hline Day 1 & $95.7 \pm 1.9$ & $\mathrm{ND}$ & $\mathrm{ND}$ \\
Day 2 & $94.1 \pm 4.1$ & $96.2 \pm 0.9$ & $\mathrm{ND}$ \\
Day 3 & $95.5 \pm 3.6$ & $\mathrm{ND}$ & $97.9 \pm 1.4$
\end{tabular}

Extr. Rec. extraction recovery 
Table 3 Summary of pharmacokinetic data carboplatin-derived unbound platinum in plasma and tissue

\begin{tabular}{|c|c|c|c|c|c|c|}
\hline Parameter & Patient 1 & Patient 2 & Patient 3 & Patient 4 & Patient 5 & Patient 6 \\
\hline Dose carboplatin (mg) & 700 & 1,150 & 850 & 780 & 700 & 780 \\
\hline Dose platinum (mg) & 368 & 604 & 447 & 410 & 368 & 410 \\
\hline \multicolumn{7}{|l|}{ Plasma } \\
\hline$C_{\max }(\mu \mathrm{g} / \mathrm{mL})$ & 25.0 & 21.7 & 27.1 & 23.8 & 19.3 & 18.8 \\
\hline $\operatorname{AUC}_{0-\text { inf }}((\mu \mathrm{g} \mathrm{h}) / \mathrm{mL})^{\mathrm{a}}$ & 63.3 & 57.0 & 59.6 & 74.2 & 41.0 & 53.1 \\
\hline $\mathrm{CL}(\mathrm{L} / \mathrm{h})$ & 5.81 & 10.6 & 7.50 & 5.53 & 8.98 & 7.72 \\
\hline$T_{\mathrm{z}}^{1 / 2}(\mathrm{~h})$ & 4.13 & 4.02 & 4.97 & 5.41 & 4.04 & 4.05 \\
\hline \multicolumn{7}{|l|}{ Tumor tissue } \\
\hline Probe recovery $(\%)^{\mathrm{b}}$ & $\begin{array}{l}44.8 \pm 2.5 \\
\quad(41.9-46.3 ; 3)\end{array}$ & $\begin{array}{l}59.9 \pm 2.3 \\
\quad(54.6-60.1 ; 5)\end{array}$ & $\begin{array}{l}69.3 \pm 1.8 \\
\quad(66.5-71.5 ; 5)\end{array}$ & $\begin{array}{l}75.8 \pm 4.4 \\
\quad(70.1-80.5 ; 5)\end{array}$ & $\begin{array}{l}52.2 \pm 2.0 \\
\quad(49.6-53.9 ; 5)\end{array}$ & $\begin{array}{l}74.4 \pm 4.0 \\
\quad(68.1-77.6 ; 5)\end{array}$ \\
\hline$C_{\max }(\mu \mathrm{g} / \mathrm{mL})$ & 21.7 & 21.3 & 24.8 & 13.9 & 13.4 & 18.3 \\
\hline $\operatorname{AUC}_{0-\text { inf }}((\mu \mathrm{gh}) / \mathrm{mL})^{\mathrm{a}}$ & 64.3 & 62.5 & 65.6 & 47.2 & 33.9 & 57.4 \\
\hline$T_{\mathrm{z}}^{1 / 2}(\mathrm{~h})$ & 3.64 & 3.85 & 2.70 & 5.68 & 3.71 & 3.08 \\
\hline \multicolumn{7}{|l|}{ Adipocytic normal tissue } \\
\hline Probe recovery $(\%)^{\mathrm{b}}$ & $\mathrm{NA}^{\mathrm{c}}$ & $\begin{array}{l}25.5 \pm 1.2 \\
\quad(24.1-26.9 ; 4)\end{array}$ & $\begin{array}{l}62.9 \pm 5.4 \\
\quad(53.8-68.2 ; 5)\end{array}$ & $\begin{array}{l}49.6 \pm 2.7 \\
\quad(46.5-53.9 ; 5)\end{array}$ & $\begin{array}{l}17.3 \pm 9.9^{\mathrm{d}} \\
\quad(10.1-34.5 ; 5)\end{array}$ & $\begin{array}{l}10.8 \pm 9.8^{\mathrm{e}} \\
\quad(21.1 \rightarrow 0.4 ; 5)\end{array}$ \\
\hline$C_{\max }(\mu \mathrm{g} / \mathrm{mL})$ & NA & 25.5 & 19.6 & 12.5 & NA & NA \\
\hline $\operatorname{AUC}_{0-\text { inf }}((\mu \mathrm{gh}) / \mathrm{mL})^{\mathrm{a}}$ & NA & 83.5 & 51.5 & 52.9 & NA & NA \\
\hline$T_{\mathrm{z}}^{1 / 2}(\mathrm{~h})$ & NA & 3.50 & 4.26 & 4.37 & NA & NA \\
\hline \multicolumn{7}{|l|}{ Ratio’s } \\
\hline AUC tumor/plama & 1.02 & 1.10 & 1.10 & 0.64 & 0.83 & 1.08 \\
\hline AUC adip. tissue/plasma & NA & 1.46 & 0.86 & 0.71 & NA & NA \\
\hline
\end{tabular}

$C_{\max }$ maximum observed concentration, $A U C$ area under the concentration time curve, $C L$ clearance, $T_{\mathrm{z}}^{1 / 2}$ terminal disposition half-life, $N A$ not available

${ }^{\text {a }}$ Calculated using observed data up to $24 \mathrm{~h}$ after start of infusion

b Mean \pm SD (range; number of observations)

${ }^{c}$ Leakage of probe observed

${ }^{\mathrm{d}}$ Fluctuating and high flow of perfusate

${ }^{\text {e }}$ Highly variable recovery decreasing in subsequent samples

those drugs with a relative slow clearance such as carboplatin.

With regard to the obtained pharmacokinetic data, results show fairly identical PK curves of unbound carboplatin at both the tumor site and in plasma. Although consistent with previous findings of Blochl-Daum et al. [8] in which PK data were obtained only up to $4 \mathrm{~h}$ after administration of carboplatin, the similar AUCs of unbound carboplatin in plasma and tumor ECF of all studied patients were unexpected. For carboplatin, internalization of the compound into (the nucleus of) the cell is necessary in order to induce the formation of toxic platinum-DNA adducts, resulting in cell cycle arrest and/or cell death [22]. Due to fragile vasculature which is more permeable than normal vasculature, the interstitial fluid pressure (IFP) is known to be increased in many solid tumors compared to adjacent normal tissue. This increased IFP forms a barrier for transcapillary transport thereby impairing the uptake of cytotoxic agents [23]. A high tumor IFP is associated with a poor prognosis in breast cancer [24, 25], colorectal cancer [24], melanomas [26] and head and neck tumors [27]. A potentially increased IFP at the tumor site was thought to be reflected by differences between tumor and plasma exposures of unbound platinum in our study. A possible explanation for the unexpected similarity between plasma and tumor pharmacokinetics could be the co-administration of dexamethasone. Dexamethasone (10 $\mathrm{mg})$ - given as standard anti-emetic treatment-has been shown to lower the IFP of tumors [28] as a consequence of which carboplatin penetration into the tumor lesions could be facilitated. This was demonstrated in a rat model in which the IFP of tumors was significantly lowered after administration of high-dose dexamethasone resulting in an increase in the uptake of 5-fluorouracil and in a significant reduction of tumor size compared to controls [29].

The recovery in normal subcutaneous adipose tissue was fluctuating, raising concerns about the feasibility to use microdialysates from normal adipose tissue as controls. Theoretically, this could be related to a problematic 

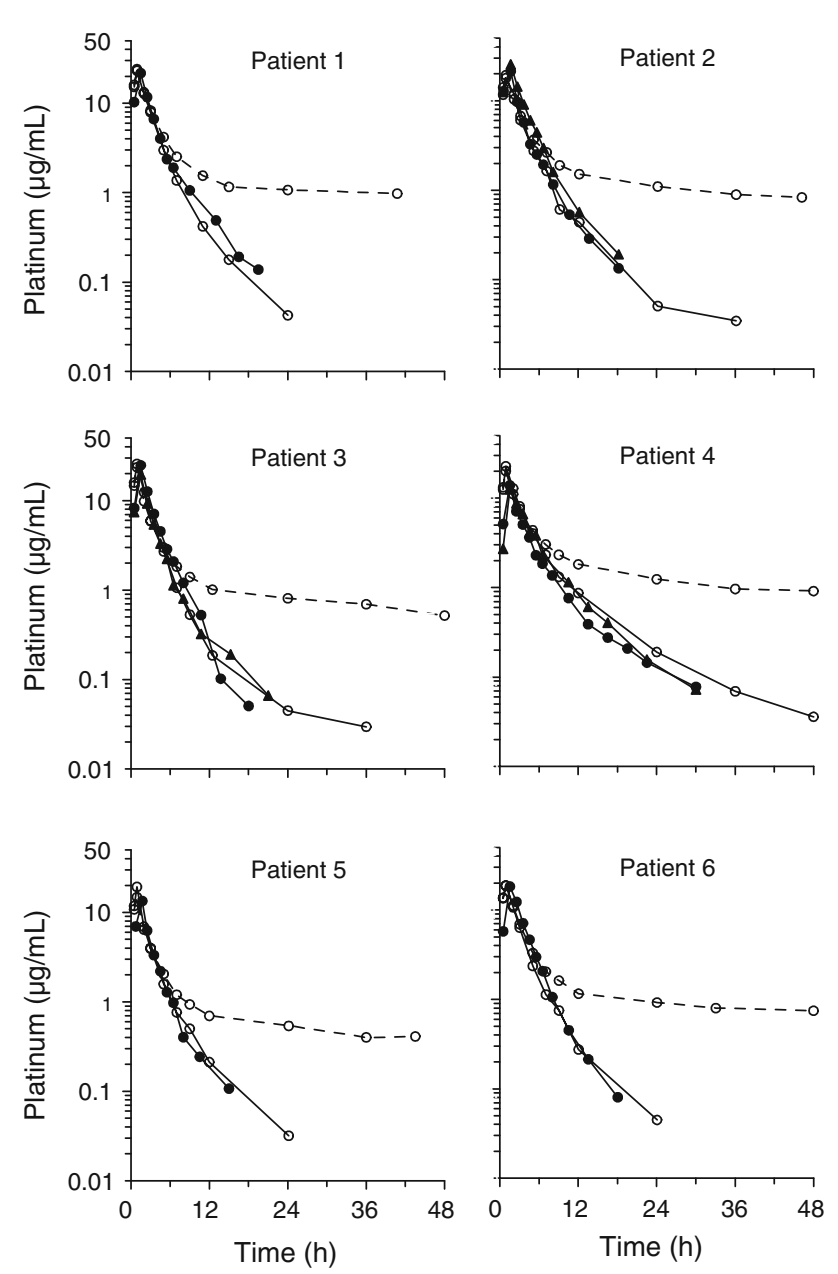

Fig. 3 Concentration-time curves of carboplatin-derived total platinum in plasma (open circles, dashed line) and unbound platinum in plasma (open circles, solid line), ECF of tumor (filled circles) and ECF of normal adipose tissue (filled triangles) in the six evaluable patients

catheter implantation with possible disruption of the dialysis membrane, though the implantation procedures were all carried out quickly without complications. Moreover, recovery was stable in tumor tissue, where catheter implantation took place in a similar manner. The underlying mechanisms of the relatively low, variable and overtime decreasing recoveries in adipose normal tissue remain to be unraveled. A possible explanation could be that subcutaneous tissue is poorly vascularized compared to tumor tissue and/or the occurrence of local vasoconstriction during the course of the experiments. Further research will be necessary to evaluate the definite role of microdialysis in subcutaneous normal tissue.

As ECF sampling in tumor tissue using microdialysis is feasible for multiple days, microdialysis might be a valuable tool in clinical trials. For instance, it could be implemented to study intra-tumoral release of drugs from liposomes or nanosomes. The applicability has been shown recently in preclinical models for SPI-077, a liposomal formulation of cisplatin. In contrast to conventional cisplatin, platinum was not detectable in the ECF of tumor tissue after the administration of SPI-077, despite sufficient tumor penetration of the liposomes [30]. Another potential application area of microdialysis involves the study of tissue-specific distribution and metabolism. Enhanced tumor concentrations of anticancer drugs, e.g. irinotecan, may be achieved by the administration of prodrugs, which have to be activated into active metabolites by enzymes in the tumor. In addition, microdialysis sampling could be helpful in further disentangling the exact sites of metabolism. Microdialysis may also be applied to unravel pharmacokinetic-response relationships. For example, in vivo experiments studying topotecan penetration in two neuroblastoma xenografts showed that topotecan exposure in the ECF of the relative sensitive xenograft was 3.5-fold greater compared to the relative resistant xenograft while plasma exposures were equivalent. This suggests that the sensitivity of the xenografts to topotecan is partly related to the extent of tumor penetration of the drug [31].

In conclusion, we showed the feasibility of microdialysis in ambulant patients for multiple days, which enables to study tissue pharmacokinetics of anticancer drugs in normal and malignant tissues in more detail. Microdialysis could become an important method to measure drug concentrations at the site of action, as the procedure is relatively simple with no restrictions in mobilization of patients, while data can be obtained with only one catheter in situ for several days. Nevertheless, it should be mentioned that, although microdialysis is a sensitive tool and enables one to obtain unique intra-tumoral PK information over time, it is still subject to some technical challenge. The failed collection of microdialysis data in $2 / 8$ patients exemplifies the limitation of this technique. The data presented in this study are still limited given the small number of patients and the high variability in patients. Despite the high variability, an estimation of the range of drug delivery to tumor is achieved and this allows clinical determination if a "minimum" of required concentration is achieved.

In the future, microdialysis could be valuable for additional PK/PD information in studies evaluating, for example, liposome- and immunoliposome-based cancer therapeutics or other carrier-mediated anticancer agents. The use of microdialysis may also be helpful in optimizing dosing and administration schedules of anticancer agents in the selection of new cytotoxic agents with the most favorable delivery profile and to gain more insights into mechanisms conferring drug resistance.

Acknowledgments We thank Conny van Noort and Mei-Ho Lam for their support to make this work possible. The Cornelis Vrolijk 
Stichting (IJmuiden, The Netherlands) is kindly acknowledged for their financial support.

Conflict of interest statement The authors declare no conflict of interest.

Open Access This article is distributed under the terms of the Creative Commons Attribution Noncommercial License which permits any noncommercial use, distribution, and reproduction in any medium, provided the original author(s) and source are credited.

\section{References}

1. Zamboni WC, Strychor S, Joseph E, Parise RA, Egorin MJ, Eiseman JL (2008) Tumor, tissue and plasma pharmacokinetic studies and antitumor response studies of docetaxel in combination with 9-nitrocamptothecin in mice bearing SKOV-3 human ovarian xenografts. Cancer Chemother Pharmacol 62:417-426

2. Zamboni WC, Strychor S, Joseph E, Walsh DR, Zamboni BA, Parise RA, Tonda ME, Yu NY, Engbers C, Eiseman JL (2007) Plasma, tumor, and tissue disposition of STEALTH liposomal CKD-602 (S-CKD602) and nonliposomal CKD-602 in mice bearing A375 human melanoma xenografts. Clin Cancer Res 13:7217-7223

3. Zamboni WC, Houghton PJ, Hulstein JL, Kirstein M, Walsh J, Cheshire PJ, Hanna SK, Danks MK, Stewart CF (1999) Relationship between tumor extracellular fluid exposure to topotecan and tumor response in human neuroblastoma xenograft and cell lines. Cancer Chemother Pharmacol 43:269-276

4. Müller M (2002) Science, medicine, and the future: microdialysis. Br Med J 324:588-591

5. Müller M, Mader RM, Steiner B et al (1997) 5-Fluorouracil kinetics in the interstitial tumor space: clinical response in breast cancer patients. Cancer Res 57:2598-2601

6. Mader RM, Schrolnberger C, Rizovski B et al (2003) Penetration of capecitabine and its metabolites into malignant and healthy tissues of patients with advanced breast cancer. $\mathrm{Br} \mathrm{J}$ Cancer 88:782-787

7. Tegeder I, Brautigam L, Seegel M et al (2003) Cisplatin tumor concentrations after intra-arterial cisplatin infusion or embolization in patients with oral cancer. Clin Pharmacol Ther 73:417426

8. Blochl-Daum B, Müller M, Meisinger V et al (1996) Measurement of extracellular fluid carboplatin kinetics in melanoma metastases with microdialysis. Br J Cancer 73:920-924

9. Joukhadar C, Klein N, Mader RM et al (2001) Penetration of dacarbazine and its active metabolite 5-aminoimidazole-4-carboxamide into cutaneous metastases of human malignant melanoma. Cancer 92:2190-2196

10. Ekström PO, Andersen A, Saeter G et al (1997) Continuous intratumoral microdialysis during high-dose methotrexate therapy in a patient with malignant fibrous histiocytoma of the femur: a case report. Cancer Chemother Pharmacol 39:267-272

11. Müller M, Brunner M, Schmid R et al (1998) Interstitial methotrexate kinetics in primary breast cancer lesions. Cancer Res 58:2982-2985

12. Long DF, Repta AJ (1981) Cisplatin: chemistry, distribution and biotransformation. Biopharm Drug Dispos 2:1-16
13. Calvert AH, Newell DR, Gumbrell LA et al (1989) Carboplatin dosage: prospective evaluation of a simple formula based on renal function. J Clin Oncol 7:1748-1756

14. Müller M, Schmid R, Georgopoulos A et al (1995) Application of microdialysis to clinical pharmacokinetics in humans. Clin Pharmacol Ther 57:371-380

15. Chaurasia CS, Müller M, Bashaw ED et al (2007) AAPS-FDA Workshop White Paper: microdialysis principles, application and regulatory perspectives. Pharm Res 24:1014-1025

16. Ault JM, Riley CM, Meltzer NM et al (1994) Dermal microdialysis sampling in vivo. Pharm Res 11:1631-1639

17. Kitzen JJ, Verweij J, Wiemer EA et al (2006) The relevance of microdialysis for clinical oncology. Curr Clin Pharmacol 1:255-263

18. Loos WJ, Zamboni WC, Engels FK et al (2007) Pitfalls of the application of microdialysis in clinical oncology: controversial findings with docetaxel. J Pharm Biomed Anal 45:288-294

19. Loos WJ, de Jongh FE, Sparreboom A et al (2006) Evaluation of an alternate dosing strategy for cisplatin in patients with extreme body surface area values. J Clin Oncol 24:1499-1506

20. Ma J, Stoter G, Verweij J, Schellens JH (1996) Comparison of ethanol plasma-protein precipitation with plasma ultrafiltration and trichloroacetic acid protein precipitation for the measurement of unbound platinum concentrations. Cancer Chemother Pharmacol 38:391-394

21. Johnsson A, Björk H, Schütz A, Skärby T (1998) Sample handling for determination of free platinum in blood after cisplatin exposure. Cancer Chemother Pharmacol 41:248-251

22. Wang D, Lippard SJ (2005) Cellular processing of platinum anticancer drugs. Nat Rev Drug Discov 4:307-320

23. Heldin CH, Rubin K, Pietras K et al (2004) High interstitial fluid pressure-an obstacle in cancer therapy. Nat Rev Cancer 4:806813

24. Less JR, Posner MC, Boucher Y et al (1992) Interstitial hypertension in human breast and colorectal tumors. Cancer Res 52:6371-6374

25. Nathanson SD, Nelson L (1994) Interstitial fluid pressure in breast cancer, benign breast conditions, and breast parenchyma. Ann Surg Oncol 1:333-338

26. Boucher Y, Kirkwood JM, Opacic D et al (1991) Interstitial hypertension in superficial metastatic melanoma in humans. Cancer Res 51:6691-6694

27. Gutmann R, Leunig M, Feyh J, Goetz AE et al (1992) Interstitial hypertension in head and neck tumors in patients: correlation with tumor size. Cancer Res 52:1993-1995

28. Kristjansen PE, Boucher Y, Jain RK (1993) Dexamethasone reduces the interstitial fluid pressure in humon colon adenocarcinoma xenograft. Cancer Res 53:4764-4766

29. Stuhr LEB, Salnikow AV, Iversen VV et al (2006) High-dose, short-term, anti-inflammatory treatment with dexamethasone reduces tumorgrowth and augments the effects of 5-fluorouracil on dimethyl- $\alpha$-benzanthrace-induced mammary tumors in rats. Scand J Clin Lab Invest 66:477-486

30. Zamboni WC, Gervais AC, Egorin MJ et al (2004) Systemic and tumor disposition of platinum after administration of cisplatin or STEALTH liposomal-cisplatin formulations (SPI-077 and SPI077 B103) in a preclinical tumor model of melanoma. Cancer Chemother Pharmacol 53:329-336

31. Zamboni WC, Stewart CF, Thompson J et al (1998) Relationship between topotecan systemic exposure and tumor response in human neuroblastoma xenografts. J Natl Cancer Inst 90:505-511 